\title{
Does Darker Hide More Knowledge? The Relationship between Machiavellianism and Knowledge Hiding
}

\author{
Wei Pan, Yang Zhou and Qingpu Zhang* \\ School of Management, Harbin Institute of Technology \\ panwei0031@163.com; 14B910014@hit.edu.cn; *zqp2015@hotmail.com
}

\begin{abstract}
Machiavellianism is deemed as one of the dark personalities. Knowledge hiding refers to employee's intentional attempt to withhold or conceal knowledge that has been requested by another person, and it is comprised of three related sub-dimensions: playing dumb, evasive hiding, and rationalized hiding. The present research examines the relationship between Machiavellianism and knowledge hiding, as well as the moderating roles of demographic variables (gender, age, and educational level). 360 individual data were used to test our hypotheses. Results show that Machiavellianism is positively related to the overall knowledge hiding, playing dumb, and evasive hiding, but unrelated to rationalized hiding. In addition, employees' knowledge hiding decreases with age. The moderating effects of demographic variables are not supported in this study. Contributions, limitations, and future directions are discussed at the end.
\end{abstract}

Keywords: Knowledge hiding; Machiavellianism; dark personality

\section{Introduction}

Scholars and practitioners' interest in the topic of knowledge sharing has exploded for decades, as witnessed by the growing body of literature in this field and increasing implementation of knowledge management system in companies. The likely reasons underlying this trend may be that employee must be motivated to share and transfer knowledge within organization, and knowledge sharing can drive individual and team creative process, and enable companies acquire sustainable competitive advantage. However, despite great effort has been put forth, it seems that employees' unwillingness to share knowledge is still overwhelming [1]. Moreover, employees even intentionally hide their knowledge from colleagues or withhold knowledge in workplace [1]. Connelly et al. (2012), for the first time, proposed and developed the novel construct of knowledge hiding to capture the phenomenon of an individual's intentional behaviour of withholding or concealing knowledge that has been requested by another individual [2]. People can engage in knowledge hiding by three different ways: playing dumb (i.e., the hider pretends to be ignorant of the knowledge), evasive hiding (the hider provides unrelated information, or misleading promise, but does not intend to tell the seeker), rationalized hiding (the hider provides a rational hiding reason, such as confidentiality) [2-3]. Ever since, researchers have realized that knowledge hiding is distinct from knowledge sharing, and argue it may be an alternative to explain why so many knowledge sharing initiatives failed. Knowledge hiding has gradually become a new research stream in organizational behaviour field with many unsolved problems, such as why people hide their knowledge, and how to reduce and eliminate knowledge hiding in organization.

With specific regard to antecedents of knowledge hiding, researchers have embraced organizational trust theory, psychological ownership theory, social exchange theory, social cognitive theory, big five personality traits, and Wuli-Shili-Renli System Approach to predict knowledge hiding in organizations. Connelly et al. (2012) argues knowledge 
owner is likely to hide knowledge from those they distrust because of the unpredictable behaviour of the other side [2]. Referring to psychological ownership theory, Peng (2013) proposes that knowledge workers are easily to generate psychological ownership feeling toward knowledge, which results in territory behaviour to protect their knowledge power, and finally drive them to hide knowledge from the requestor [4]. Drawn on social exchange and social cognitive theory, Lin and Huang (2010), Tasy et al. (2014) examine how organizational justice and task characteristics affect knowledge withholding intention in team context [5-6]. They find that organizational justice indirectly influence knowledge withholding intentions through the mediation of social exchange variables, such as perceived organizational support, leader-member exchange, and team-member exchange. In addition, two task variables, task interdependence and task visibility, influence knowledge withholding intention through knowledge withholding self-efficacy. Wang et al. (2014) examine the relationship between big five personality traits and knowledge withholding, and their results indicate that extraversion, conscientiousness, neuroticism, and openness to experience indirectly influence knowledge withholding intention through the mediation of perceived social identity [7]. Pan and Zhang (2014) adopt the WuliRenli-Shili System Approach, an oriental system thinking, to systematically delve into factors of knowledge hiding among graduate students. They find factors of knowledge hiding come from three aspects: Wuli-characteristics of knowledge, Shiliorganizational regulation, environment, and Renli-knowledge owner, seeker, and interpersonal dynamics [8].

To sum up, lots of perspectives have been applied to investigate influencing factors of knowledge hiding behavior, and those works have made great contribution for us to understand the nature of knowledge hiding. However, one concept that seems to be particularly suited to examine this behaviour but has been overlooked is the notion of Machiavellianism, one dark personality. This work tries to fill this research gap. For a long time, organizational behavior scholars have deemed individual's behavior within workplace has its personality root. On one hand, lots of works have been conducted to link the positive personalities, such as Big Five, optimism, integrity, and self-authenticity, internal locus of control, and among others, to individual positive behaviors, such as helping, ethical behavior, and organizational citizenship behavior. On the other hand, studies of counterproductive workplace behaviors, such as employee theft, opportunity behavior, abusive supervision, and so on, have attested to the dark side of human personality, such as Machiavellianism [9].

Knowledge hiding which refers to an intentional attempt to conceal or withhold knowledge that is requested by others [2], is deemed as one counterproductive knowledge behavior [10]. However, thus far, few research have examined the relationship between individual personality and knowledge hiding [1][7]. We speculate that one personality influencing knowledge hiding is Machiavellianism. To our knowledge, our study is the first empirical study to address the relationship between Machiavellianism and knowledge hiding, and highlights the individual difference on knowledge hiding.

\section{Literature Review and Hypotheses Development}

\subsection{Machiavellianism and Knowledge Hiding}

Machiavellianism was named after the philosophy of Niccolo Machiavelli, a political advisor to the Medici family in the 1500s. In his book The Prince, Niccolo Machiavelli points out that politicians can use every possible means to expand the country's strength. Later, Christie and Geis contend that ordinary people can also use immoral and manipulative tactics to get their way. Machiavellianism refers to one's predisposition to utilize manipulative and deceitful interpersonal tactics, hold 
a cynical and untrustworthy view of human nature, and act amorally [11]. This construct was originally proposed and developed by Christie and Geis during their studies on political and religious extremist groups [12]. Soon afterward, Machiavellianism was brought into the study of organizational behaviour. Machiavellians individuals are characterized with self-centred, interpersonal coldness, deceitful, immoral belief, manipulative, and cynical view of human nature [11] [13].

Although no works have directly examined the relationship between Machiavellianism and knowledge hiding, existing research on Machiavellianism and other behavioural variables (cooperation, helping behaviour, unethical behaviour) might indicate that Machiavellianism plays a role in predicting knowledge hiding. Paal and Bereczkei (2007) confirm that Machiavellianism is negatively related to cooperation because they hold a cynical view of others, doubt others' intension, and distrust others [14]. Wolfson (1981) provides evidence that High Machiavellians are less likely to conduct helping behaviour compared to low Machiavellians [15]. Zagenczyk et al. (2014) conduct four studies in multiple contexts, and conclude Machiavellianism is negatively related to organizational citizenship behaviours but positively related to workplace deviant behaviours through the mediator of economic psychological contract [16]. What is more, Liu (2008) finds a negative relationship between Machiavellianism and knowledge sharing [17]. Although knowledge hiding is not an entirely negative behaviour, it is to a large extent one unethical behaviour, and has overlap with deviant behaviour [2] [18]. When asked for knowledge, individuals with high Machiavellianism are more likely to refuse to help, not to cooperate, therefore, exhibit more knowledge hiding. Thus, it is rational to hypothesize,

Hypothesis 1: Machiavellianism is positively related to knowledge hiding.

\subsection{Moderating Roles of Demographic Variables}

Prior research suggests that demographic variables (gender, age, education level) may play moderating effects on the relationship between Machiavellianism and knowledge hiding. For example, Brown \& Guy (1983) draw a conclusion that there is an interaction effect of sex-Machiavellian on self-disclosure [19]. Domelsmith et al. (1978) contends Machiavellianism is negatively related to willingness to selfdisclosure for male, while positively for female [20]. Pratt et al. (1983) argues that because of generation gap, young people tend to lack the consistency on moral judgement, while old people are more organized and consistent [21]. This means with the increase of age, the old have developed the mature moral judgments. Allmon et al. (2000) also hold the view that ethical beliefs increase with age both for male and female [22]. Previous research also suggests that individuals with higher education level behave more ethically [23]. Thus, we propose the following hypotheses,

Hypothesis 2: Gender moderates the relationship between Machiavellianism and knowledge hiding in that male Machiavellianism is positively related to knowledge hiding while female Machiavellianism is negatively related to knowledge hiding.

Hypothesis 3: Age moderates the relationship between Machiavellianism and knowledge hiding in that the older an individual, the weaker will be the positive effect of Machiavellianism on knowledge hiding.

Hypothesis 4: Educational level moderates the relationship between Machiavellianism and knowledge hiding in that the higher the educational level, the weaker will be the positive effect of Machiavellianism on knowledge hiding.

Consequently, the objective of this study is to advance prior research by examine the relationship between Machiavellianism and knowledge hiding, and explore whether demographic variables act as moderators in the relationship. 


\section{Methods}

\subsection{Participants and Procedure}

Participants were employees from two IT companies in mainland China. Before the survey, we told participants that this survey is used for research only and their information and answers would be strictly confidential. We promised that participating the survey would not impact on their job in the companies. Participants were asked to put the finished questionnaires into a box in the corner of the company. In total, 360 valid questionnaires were gathered. Of the 360 usable participants, about 55.6 percent were male; 41.9 percent were between 30 years of age to 39 years of age; 66.7 percent had a bachelor or above degree.

\subsection{Measures}

As all the scales are originally English scales, the translation-back translation method was followed to translate them into Chinese scales. Two English major graduate students were recruited to translate them into Chinese, and another two English major graduate students translated them back into English.

Machiavellianism. Machiavellianism was measured with the most frequently used 20-item Mach-IV scale developed by Christie \& Geis [11]. Participants were asked to answer to what extent they would agree with the items. Sample items include "it is wise to flatter important people", and "most people are basically good and kind (Reversed)". Respondents completed the measures using a 7-point Likert scale ( $1=$ strongly disagree, $7=$ strongly agree). The reliability Cronbach's alpha was 0.686, which is acceptable referring to previous studies [24-25].

Knowledge hiding. A 12-item scale developed by Connelly et al. [2], and used by Černe et al. (2014) was adopted to measure knowledge hiding [18]. Each dimension of knowledge hiding was measured with 4 items. These items were self-reported by participants to assess the extent to which they would hide knowledge form colleagues. The scale opened with following sentences: "In a specific episode in which some particular co-worker requested knowledge from you and you may ..." A sample item for playing dumb is "pretended that I did not know the knowledge". A sample item for evasive hiding is "I told him/her that I would help him/her out later but stalled as much as possible". A sample item for rationalized hiding is "explained that the information is confidential and only available to people on particular project". Respondents completed the measures using a 7-point Likert scale (1=strongly disagree, $7=$ strongly agree). The reliability Cronbach's alpha of overall knowledge hiding was 0.889 . The Cronbach's alphas of the subscales were $0.805,0.904,0.811$ for playing dumb, evasive hiding, and rationalized hiding, respectively.

Demographic variables. Gender, age, and educational level were self-reported by participants. Gender was coded as a dummy variable, and age and educational level were coded as continuous variables. Men were coded 1, and women were coded 0. Age was coded 1 for "less than 24 years old," 2 for " 25 to 29 years old," 3 for "30 to 39 years old," 4 for " 40 to 49 years old," and 5 for "above 50 years old." Educational level was coded 1 for "high school and under," 2 for "junior college," 3 for "bachelor," 4 for "master and above".

\subsection{Data Analysis}

We first calculated the correlations between focal variables by Pearson correlations. Then, the hierarchical regression method was used to examine the relationship between Machiavellianism and knowledge hiding, as well as the moderating role of demographic variables. 


\section{Results}

Table 1 shows the means, standard deviations, and correlations of the variables. Machiavellianism is positively correlated with knowledge hiding $(\gamma=0.292, \mathrm{P}<0.01)$ which provides preliminary support of Hypothesis 1. Age is negatively correlated with knowledge hiding $(\gamma=-0.124, \mathrm{P}<0.05)$.

Table 1. Means, Standard Deviations and correlations of variables

\begin{tabular}{|l|c|c|c|c|c|c|c|c|}
\hline Variable & 1 & 2 & 3 & 4 & 5 & 6 & 7 & 8 \\
\hline 1.Gender & - & & & & & & & \\
\hline 2.Age & $.119 *$ & - & & & & & & \\
\hline 3.Education & -.001 & $-.115^{*}$ & - & & & & & \\
\hline 4. Mach & $-.127 *$ & -.006 & .023 & - & & & & \\
\hline $5 . \mathrm{KH}$ & -.034 & $-.124 *$ & .074 & $.292^{* *}$ & - & & & \\
\hline 6.PD & -.052 & -.051 & -.010 & $.315^{* *}$ & $.805^{* *}$ & - & & \\
\hline 7.EH & -.033 & $-.160 * *$ & .089 & $.339 * *$ & $.852 * *$ & $.543 * *$ & - & \\
\hline $8 . \mathrm{RH}$ & .004 & -.077 & .094 & .037 & $.773 * *$ & $.449 * *$ & $.469 * *$ & - \\
\hline Mean & .555 & 3.441 & 2.656 & 3.775 & 3.903 & 3.946 & 3.492 & 4.272 \\
\hline SD & .498 & .968 & .734 & 0.464 & 0.942 & 1.076 & 1.316 & 1.086 \\
\hline
\end{tabular}

Note: $n=360 ; * p<0.05 ; * * p<0.01$; two-tailed; Mach=Machiavellianism; KH=knowledge hiding; $P D=$ playing dumb; $E H=$ evasive hiding; $R H=$ rationalized hiding

Hierarchical regression method was utilized to test our hypotheses. SPSS 22 was employed to process the data. Table 2 shows the regression results. In model 1 , knowledge hiding was regressed on demographic variables only. Results showed only age was negatively related to knowledge hiding $(\beta=-0.114, \mathrm{P}<0.05)$. In Model 2 and Model 3, we found the positive relationship between Machiavellianism and knowledge hiding (Model 2, $\beta=0.292, \mathrm{P}<0.001$; Model 3, $\beta=0.688, \mathrm{P}<0.05$ ), which supported Hypothesis 1. Participants with high score on Machiavellianism are more likely to hide knowledge from knowledge seeker than those with low score on Machiavellianism. In model 3, we added the interaction terms into the regression model. Results showed that the $\Delta \mathrm{R}^{2}$ did not reach the statistical significance. Thus, the demographic variables did not play moderating effects in the relationship between Machiavellianism and knowledge hiding. What is more, when we used three sub-dimensions of knowledge hiding (playing dumb, evasive hiding, rationalized hiding) as dependent variables, the interaction items were also not statistically significant. Therefore, hypotheses 2,3 , and 4 were not supported in our study. However, in all three models in Table 2, age is negatively related to knowledge hiding (Model 1, $\beta=-0.114, \mathrm{P}<0.05$; Model 2, $\beta=-0.118, \mathrm{P}<0.05$; Model $3, \beta=-0.117, \mathrm{P}<0.05)$.

Table 2. Results of Hierarchical Regression Analysis

\begin{tabular}{|l|c|c|c|}
\hline \multirow{2}{*}{ Variable } & \multicolumn{3}{|c|}{ Knowledge hiding } \\
\cline { 2 - 4 } & Model 1 & Model 2 & Model 3 \\
\hline Gender & -0.020 & 0.018 & 0.025 \\
\hline Age & $-0.114^{*}$ & $-0.118^{*}$ & $-0.117^{*}$ \\
\hline Education & 0.061 & 0.054 & 0.050 \\
\hline Mach & & $0.292^{* * *}$ & $0.688^{*}$ \\
\hline Mach $\times$ Gender & & & -0.034 \\
\hline Mach $\times$ Age & & & $-0.368+$ \\
\hline Mach $\times$ Education & & & -0.016 \\
\hline $\mathrm{R}^{2}$ & 0.019 & 0.103 & 0.115 \\
\hline $\mathrm{F}$ & $2.335+$ & $10.199^{* * *}$ & $6.539 * * *$ \\
\hline
\end{tabular}


\begin{tabular}{|l|l|r|r|}
\hline$\Delta \mathrm{R}^{2}$ & $0.084 * * *$ & 0.012 \\
\hline
\end{tabular}

Note: $n=360 ;$ standardized coefficient was reported, ${ }^{+} P<0.1 ;{ }^{*} p<0.05 ; *^{*} p<0.01 ; * * * p<0.001$;

Mach=Machiavellianism

In order to investigate why Machiavellianism could predict knowledge hiding, we further examine the relationship between Machiavellianism and three subdimensions of knowledge hiding (playing dumb, evasive hiding, rationalized hiding). First, the explanatory factor analysis (principal component with the maximum variance method) was used to test the validity of knowledge hiding. The results of explanatory factor analysis of knowledge hiding items were shown in Table 3.

Table 3. Explanatory Factor Analysis of Knowledge Hiding Items

\begin{tabular}{|l|c|c|c|}
\hline \multirow{2}{*}{ Item } & \multicolumn{3}{|c|}{ Factor } \\
\cline { 2 - 4 } & 1 & 2 & 3 \\
\hline Playing dumb 1 & 0.213 & 0.074 & $\mathbf{0 . 8 2 1}$ \\
\hline Playing dumb 2 & 0.327 & 0.133 & $\mathbf{0 . 7 6 7}$ \\
\hline Playing dumb 3 & 0.509 & 0.098 & $\mathbf{0 . 6 4 9}$ \\
\hline Playing dumb 4 & -0.039 & 0.399 & $\mathbf{0 . 6 9 0}$ \\
\hline Evasive hiding 1 & $\mathbf{0 . 8 0 3}$ & 0.185 & 0.180 \\
\hline Evasive hiding 2 & $\mathbf{0 . 8 6 3}$ & 0.137 & 0.181 \\
\hline Evasive hiding 3 & $\mathbf{0 . 8 0 6}$ & 0.216 & 0.214 \\
\hline Evasive hiding 4 & $\mathbf{0 . 8 6 1}$ & 0.201 & 0.177 \\
\hline Rationalized hiding 1 & 0.420 & $\mathbf{0 . 6 6 0}$ & 0.145 \\
\hline Rationalized hiding 2 & 0.085 & $\mathbf{0 . 8 3 9}$ & 0.142 \\
\hline Rationalized hiding 3 & 0.197 & $\mathbf{0 . 7 9 2}$ & 0.137 \\
\hline Rationalized hiding 4 & 0.141 & $\mathbf{0 . 7 2 3}$ & 0.121 \\
\hline Eigenvalue & 5.463 & 1.654 & 1.314 \\
\hline Variance Explained (\%) & 45.525 & 13.782 & 10.951 \\
\hline Cumulative variance (\%) & 45.525 & 59.307 & 70.258 \\
\hline
\end{tabular}

Results showed a dominant three-factor solution based on eigenvalue larger than one. Three factors explained 70.258 percent of variance. The estimate items loaded on their intended factors with the factor loading ranging from 0.649 to 0.863 . Only two cross loadings were larger than 0.400 . They are item playing dumb 3 with a cross loading 0.509 on factor 1 and item rationalized hiding 1 with a cross loading 0.420 on factor 1 . Other cross loading were less than 0.400 . Thus, it proved good convergent and discriminant validity of three sub-dimensions of knowledge hiding. Then, each dimension of knowledge hiding was regressed on Machiavellianism. The results are shown in Table 4.

\section{Table 4. Results of Dimensions of knowledge Hiding Regressed on Machiavellianism}

\begin{tabular}{|l|c|c|c|}
\hline Variable & Playing dumb & Evasive hiding & Rationalized hiding \\
\hline Gender & -0.005 & 0.028 & 0.017 \\
\hline Age & -0.051 & $-0.154 * *$ & -0.069 \\
\hline Education & -0.023 & 0.064 & 0.085 \\
\hline Machiavellianism & $0.315^{* * *}$ & $0.340 * * *$ & 0.036 \\
\hline $\mathrm{R}^{2}$ & 0.102 & 0.144 & 0.015 \\
\hline $\mathrm{F}$ & $10.128 * * *$ & $14.980 * * *$ & 1.331 \\
\hline
\end{tabular}

Note: $n=360$; standardized coefficient was reported, ${ }^{+} P<0.1 ;{ }^{*} p<0.05 ;{ }^{* *} p<0.01 ; * * * p<0.001$

Results indicated that Machiavellianism was positively related to playing dumb ( $\beta=0.315, \quad \mathrm{P}<0.001)$, and evasive hiding $(\beta=0.340, \quad \mathrm{P}<0.001)$. However, no statistically significant relationship was found between Machiavellianism and 
rationalized hiding $(\beta=0.036, \mathrm{P}=0.493)$. Thus, Machiavellianism is only positively related to playing dumb, and evasive hiding, but unrelated to rationalized hiding.

\section{Discussion}

In this study, we employed an individual difference perspective to predict knowledge hiding in organization. Specifically, we examined the relationship between Machiavellianism and knowledge hiding, as well as the moderating roles of demographic variables. The present study found a positive relationship between Machiavellianism and overall knowledge hiding. The higher employees' Machiavellianism orientations are, the more they will take strategies to hide knowledge from co-workers. This finding is not unexpected as we discussed the theoretical background in the literature review and hypotheses development part. It is consistent with previous studies on the relationship between Machiavellianism and helping behaviour, counterproductive workplace behaviour, and cooperation, to some extent [14-16]. Employees with high Machiavellianism tend to hold a more cynical and untrustworthy view of human nature. When facing knowledge request from co-worker, they are more likely to doubt other's intention, distrust for other, and then hide their knowledge. Employees with high Machiavellianism are selfcentred, personally cold, care less for others' feelings, and do not believe the principle of reciprocity. Response to others' knowledge requests means they will have less time and energy to deal with their own current works. Sakalaki, Richardson, and Thepaut (2007) also demonstrated high Machiavellians were highly prone to maximize their own benefits rather than trusting and cooperating with potential economic partners [26]. Therefore, there are no benefits other than costing time and energy for high Machiavellians by disclosing knowledge to requestors. What's more, knowledge is the source of power. Disclosure knowledge to coworkers means the increase of employees' substitutability, because more people can do the same task within the organization. Employees with high Machiavellianism orientation would not let others control him/her. Because Machiavellians have desire for control, they can control the situation by keeping knowledge or information to him/herself.

The relationships between Machiavellianism and three sub-dimensions of knowledge hiding were also examined. Results indicate Machiavellianism is significantly positively related to playing dumb and evasive hiding, but unrelated to rationalized hiding. This result can be interpreted with the original conceptualization of knowledge hiding by Connelly et al. According to their definition, knowledge hiding is not a uniformly negative behaviour. When employees hide their knowledge by playing dumb and evasive hiding, their hiding behaviour usually contains lying, non-cooperation, and refusing to help. However, when they engage in knowledge hiding by rationalized hiding, their hiding behaviour may not contain deception. They might hide knowledge rationally due to organizational norm or the protection of other party's interest. According to Geis and Moon (1981), High Machiavellians are skilful liars, and lying high Machiavellians are more believed than lying low Machiavellians, while low Machiavellians tend to be more honest, upright, and pro-social [27]. Therefore, there might be no difference between high Machiavellianism and low Machiavellianism on rationalized hiding.

Our results showed the demographic variables (gender, age, and educational level) did not play moderating effects on the relationship between Machiavellianism and knowledge hiding. No specific demographic differences were found on the relationship between Machiavellianism and knowledge hiding. This might be due to the specific context of the scenario in our knowledge hiding measurement. In order 
to measure knowledge hiding, participants were called to image a scenario in which some co-worker asked for knowledge from him/her, and see what she/he would do. Each participant might put him/her in different situation with different knowledge targets. Rosenfeld, Civikly, and Herron (1979) also suggested that subject and target characteristics (such as attractiveness, sex, and age) and characteristics of situation might play as possible interventions [28].

However, we did have another interesting finding: the older employees are, the less they will hide their knowledge. This finding is consistent with prior literature on age and ethical belief, to some extent. Kohlberg (1973) developed a six-stage model of moral development [29], and Bielby and Papalia (1975) demonstrated a curvilinear development function with the highest moral judgment point at the age of 50 [30]. Kohlberg also indicated that ethical and moral thinking might be advanced with the increase of maturity and age [29]. As we have said, knowledge hiding is, to a large extent, some unethical behaviour. Therefore, moral standards increase with age and years of working experience, leading to less knowledge hiding in organization.

\section{Theoretical and Practical Implications}

So far, few researches have focused on individual differences on knowledge hiding, though it is an important aspect [1]. Our work is an important step in this regard. Therefore, this study's first theoretical contribution is to extend the literature on antecedents of knowledge hiding behaviour by investigating how such behaviour is predicted by Machiavellianism, one dark personality. Result showed that Machiavellianism is positively related to overall knowledge hiding. This result is rooted in the characteristics of Machiavellianism, such as self-centred, interpersonal coldness, deceitful, immoral belief, manipulative, and so on.

The second contribution to knowledge hiding literature is that different dimensions of knowledge hiding have different antecedents, therefore, should study separately. Existing studies often treat knowledge hiding as one overall variable. Our study shows that Machiavellianism is only positively related to playing dumb and evasive hiding, but not related to rationalized hiding. Connelly et al. (2012) also demonstrated task-relatedness is negatively related to rationalized hiding, but positively related to evasive hiding, unrelated to playing dumb [2]. These all indicate that antecedents of overall knowledge hiding indeed have different roles in different sub-dimensions of knowledge hiding and antecedents that are positive related to one dimension, can be negative for another one.

Previous studies show that individual knowledge hiding is detrimental to unit performance [31], and team creativity process [32]. Therefore, from a practical perspective, the findings of this work enable companies to develop a better selection method when building teams from existing employees within organization, allowing business to avoid potential loses and damages caused by knowledge hiding. Because when Machiavellians use their manipulative and deceitful tactics in organization, they might be noticed by other employees or supervisors. Keep those who always show some Machiavellianism orientation out of team building is extremely important. Thus, those with extremely high orientation on some personalities, such as Machiavellianism, could be screened out to reduce the number of employees who are predisposed to knowledge hiding in teams. A better selection method is especially important for those companies or teams emphasizing cooperation, communication, and sharing. 


\section{Limitations and Future Directions}

Like any other studies, this work is not without limitations. First, the current study uses self-reported scale to measure knowledge hiding. According to Connelly et al (2012), knowledge hiding is a low-rate, underreported behaviour [2]. Respondents may not be willing to report those undesirable behaviours, which cause social desirability bias. However, supervisor or co-worker reported knowledge hiding might not reflect knowledge hiding accurately because the definition of knowledge hiding involves concealment of information [18]. What is more, a recent meta-analysis conducted by Berry et al. (2012) reveals that other-reported assessments of counterproductive work behaviour, such as knowledge hiding, do not capture unique and valid incremental variance beyond what self-reports capture and may even assess such behaviour more narrowly [33]. Future research could utilize experimental study to measure knowledge hiding more accurately. For example, researchers could design a particular knowledge sharing dilemma scenario, and control the knowledge base participants could have. Then, researchers could examine what type of knowledge participants are likely to hide, and how they will hide their knowledge. By controlling the specific context in experimental studies, researchers could also re-examine the moderating effects of demographic variables on the relationship between Machiavellianism and knowledge hiding.

Second, the self-reported knowledge hiding, not the perceived knowledge hiding was examined in our study. In fact, the perpetrator and targets of knowledge hiding will construe knowledge hiding very differently [3]. Once co-worker perceives knowledge hiding, accurately or not, they will back fire at the initial hider [18]. Future research could investigate how Machiavellianism is related with co-worker's perceived knowledge hiding.

Third, the current study only examines those instances in which knowledge is requested but not shared. As employees with high Machiavellianism is highly manipulative, they might also deliberately hide those unrequested knowledge from co-workers. As Evans, Hendron \& Oldroyd (2015) states the effective knowledge transfer in organizational not only rely on granting those requested knowledge, but also rely on sharing unrequested knowledge which one has but others are unaware of [31]. Future research could develop scales to measure those instances that employees strategically hide unrequested knowledge from co-worker, and investigate how personalities influence this specific behaviour.

Forth, the current study only examines how Machiavellianism, not other personalities, related to knowledge hiding. Because Machiavellianism is one socially aversive personality; and it seems to be most related with our topic among the Dark Traid of personality. As we have state in the previous part, this work is the first step in this regard. Future research could use a more general model combing big five personality traits with the dark triad to develop a best-fitting and most parsimonious model to explain knowledge hiding behaviour.

\section{Acknowledgement}

This research is supported by the National Natural Science Foundation of China (Grants nos. 71273076, 71573064).

\section{References}

[1] J. Webster, G. Brown, D. Zweig, C. E. Connelly, S. Brodt and S. Sitkin, "Beyond knowledge sharing: Knowledge withholding at work", Edited J. J. Martocchio, Emerald Group Publishing Limited, Bradford, vol. 27, (2008), pp. 1-37.

[2] C. E. Connelly, D. Zweig, J. Webster and J. P. Trougakos, "Knowledge hiding in organizations", Journal of Organizational Behavior, vol. 33, no. 1, (2012), pp. 64-88. 
[3] C. E. Connelly and D. Zweig, "How perpetrators and targets construe knowledge hiding in organizations", European Journal of Work and Organizational Psychology, vol. 24, no. 3, (2015), pp. 479-489.

[4] H. Peng, "Why and when do people hide knowledge?", Journal of Knowledge Management, vol. 17, no. 3, (2013). pp. 398-415.

[5] T. C. Lin and C. C. Huang, "Withholding effort in knowledge contribution: the role of social exchange and social cognitive on project teams", Information \& Management, vol. 47, no.3, (2010), pp. 188-196.

[6] C. H. H. Tsay, T. C. Lin, J. Yoon and C. C. Huang, "Knowledge withholding intentions in teams: The roles of normative conformity, affective bonding, rational choice and social cognition", Decision Support Systems, vol. 67, (2014), pp. 53-65.

[7] Y. S. Wang, H. H. Lin, C. R. Li and S. J. Lin, "What drives students' knowledge-withholding intention in management education? An empirical study in Taiwan", Academy of Management Learning \& Education, vol. 13, no. 4, (2014), pp. 547-568.

[8] W. Pan and Q. Zhang, "A study on motivations of graduate students' knowledge hiding based on WuliShili-Renli system approach", Proccedings of the 2nd International Conference on Education, Management and Social Science, Tianjin, China, (2014) August 7-8.

[9] E. H. O'Boyle, D. R. Forsyth, G. C. Banks, and M. A. McDaniel, "A meta-analysis of the dark triad and work behavior: A social exchange perspective", Journal of Applied Psychology, vol. 97, no. 3, (2012). pp. 557-579.

[10] A. Serenko, N. Bontis, "Understanding counterproductive knowledge behavior: antecedents and consequences of intra-organizational knowledge hiding”, Journal of Knowledge Management, vol. 20, no. 6, (2016). pp.1199- 1224.

[11] R. Christie, and F. Geis, "Studies in Machiavellianism", San Diego, CA: Academic Press. (1970).

[12] J. J. Dahling, B. G. Whitaker, and P. E. Levy, "The development and validation of a new Machiavellianism scale", Journal of Management, vol. 35, no. 2, (2009), pp. 219-257.

[13] J. F. Rauthmann, "The Dark Triad and interpersonal perception: Similarities and differences in the social consequences of narcissism, Machiavellianism, and psychopathy", Social Psychological and Personality Science, vol. 3, no. 4, (2012), pp. 487-496.

[14] T. Paal and T. Bereczkei, "Adult theory of mind, cooperation, Machiavellianism: The effect of mindreading on social relations", Personality and Individual Differences, vol. 43, no. 3, (2007), pp. 541551.

[15] S. L. Wolfson, "Effects of Machiavellianism and communication on helping behaviour during an emergency”, British Journal of Social Psychology, vol. 20, no. 3, (1981), pp. 189-195.

[16] [16] T. J. Zagenczyk, S. L. D. Restubog, C. Kiewitz, K., Kiazad and R. L. Tang, "Psychological contracts as a mediator between Machiavellianism and employee citizenship and deviant behaviors", Journal of Management, vol. 40, no. 4, (2014), pp. 1098-1122.

[17] C. C. Liu, "The relationship between Machiavellianism and knowledge sharing willingness", Journal of Business and Psychology, vol. 22, no. 3, (2008), pp. 233-240.

[18] M. Černe, C. G. Nerstad, A. Dysvik and M. Škerlavaj, "What goes around comes around: Knowledge hiding, perceived motivational climate, and creativity", Academy of Management Journal, vol. 57, no. 1, (2014), pp.172-192.

[19] E. C. Brown, and R. F. Guy, "The effects of sex and Machiavellianism on self-disclosure patterns", Social Behavior and Personality: an international journal, vol. 11, no. 1, (1983), pp. 93-96.

[20] D. E. Domelsmith and J. T. Dietch, "Sex differences in the relationship between Machiavellianism and self-disclosure", Psychological Reports, vol. 42, no. 3, (1978), pp. 715-721.

[21] M. Pratt, G. Golding and W. Hunter, "Aging as ripening: Character and consistency of moral judgment in young, mature, and older adults", Human Development, vol. 26, no. 5, (1983), pp. 277-288.

[22] D. E. Allmon, D. Page and R. Rpberts, "Determinants of perceptions of cheating: Ethical orientation, personality and demographics". Journal of Business Ethics, vol. 23, no. 4, (2000), pp. 411-422.

[23] P. J. Toriello and J. J. Benshoff, "Substance abuse counselors and ethical dilemmas: The influence of recovery and education level", Journal of Addictions \& Offender Counseling, vol. 23, no. 2, (2003), pp. 83-98.

[24] A. Láng, "Machiavellianism and early maladaptive schemas in adolescents", Personality and Individual Differences, vol. 87, (2015). pp.162-165.

[25] G. Hodson, S. M. Hogg, and C. C. MacInnis, "The role of dark personalities" (narcissism, Machiavellianism, psychopathy), Big Five personality factors, and ideology in explaining prejudice. Journal of Research in Personality", vol. 43, no. 4, (2009). pp. 686-690.

[26] M. Sakalaki, C. Richardson and Y. Thepaut, "Machiavellianism and economic opportunism", Journal of Applied Social Psychology, vol. 37, no. 6, (2007), pp. 1181-1190.

[27] F. L. Geis and T. H. Moon, "Machiavellianism and deception", Journal of Personality and Social Psychology, vol. 41, no. 4, (1981), pp. 766-775.

[28] L. B. Rosenfeld, J. M. Civikly and J. R. Herron, “Anatomical and psychological sex differences", Edited G. J. Chelune, Jossey-Bass, San Francisco, (1979), pp. 80-109.

[29] L. Kohlberg, "Stages and aging in moral development—some speculations", The Gerontologist, vol. 13, no. 4, (1973), pp. 497-502 
[30] D. D. V. Bielby and D. E. Papalia, "Moral development and perceptual role-taking egocentrism: Their development and interrelationship across the life-span", The International Journal of Aging and Human Development, vol. 6, no. 4, (1975), pp. 293-308.

[31] J. M. Evans, M. G. Hendron and J. B. Oldroyd, "Withholding the ace: The individual-and unit-level performance effects of self-reported and perceived knowledge hoarding", Organization Science, vol. 26, no. 2, (2014), pp. 494-510.

[32] S. W. Kang, "Knowledge withholding: psychological hindrance to the innovation diffusion within an organisation", Knowledge Management Research \& Practice, vol. 14, (2016), pp. 144-149.

[33] C. M. Berry, N. C. Carpenter and C. L. Barratt, "Do other-reports of counterproductive work behavior provide an incremental contribution over self-reports? A meta-analytic comparison", Journal of Applied Psychology, vol. 97, no. 3, (2012). pp. 613-636. 
International Journal of Security and Its Applications

Vol. 10, No. 11 (2016) 